\title{
KOMPARASI ALGORITMA NAIVE BAYES, RANDOM FOREST DAN SVM UNTUK MEMPREDIKSI NIAT PEMBELANJA ONLINE
}

\author{
Cucu Ika Agustyaningrum ${ }^{1}$, Windu Gata ${ }^{2}$, Ridan Nurfalah $^{3}$, Ummu Radiyah $^{4}$, \\ Mawadatul Maulidah ${ }^{5}$ \\ ${ }^{1,2,5}$ Program Studi Ilmu Komputer, STMIK Nusa Mandiri \\ ${ }^{3}$ Program Sistem Informasi, STMIK Nusa Mandiri \\ ${ }^{4}$ Program Teknik Informatika, STMIK Nusa Mandiri \\ Jl. Kramat Raya No. 18, Jakarta Pusat, Jakarta \\ Telp. (021) 31908575 \\ e-mail : \\ ${ }^{1} 14002365 @$ nusamandiri.ac.id, ${ }^{2}$ windu @ nusamandiri.ac.id, ${ }^{3}$ ridan.rlh@ $@$ nusamandiri.ac.id, \\ ${ }^{4}$ ummu.urd@ nusamandiri.ac.id, ${ }^{5} 14002373 @$ nusamandiri.ac.id
}

\begin{abstract}
In recent years, the use of e-commerce or online shops has increased considerably. Various online stores have sprung up on the internet, both small and large-scale. This has a very important effect on the effective use of time and the level of sales figures. Therefore, e-commerce or online stores must have the ability to assess the means used to identify and classify online shopping intentions to generate profits for the store. Classification of online shopper intentions can be carried out using several algorithms, such as Naive Bayes, Random Forest, and Support Vector Machine. In this study, the comparison of algorithms was carried out using the WEKA application by knowing the value of the F1-Score, Accuracy, Kappa Statistic, and Mean Absolute Error. There is a difference between the test results, for the F1-Score, Accuracy, Kappa Statistic results in the Random Forest algorithm test which is the best compared to Naive Bayes and Support Vector Machine. While the Mean Absolute Error test results for the Support Vector Machine algorithm are the best values than Naive Bayes and Random Forest. So based on this research the Random Forest Algorithm is the best and appropriate algorithm to be applied as a classification of online shopper intentions because the Random Forest algorithm dominates in knowing the value of criteria such as F1-Score, Accuracy, Kappa Statistic, and Mean Absolute Error.
\end{abstract}

Keywords - Algorithm, E-Commerce, Machine Learning, Shopping Intention, Weka.

\section{ABSTRAK}

Beberapa tahun terakhir ini, penggunaan e-commerce atau toko online sangat meningkat. Bermacam-macam toko online yang bermunculan di internet, baik berskala kecil maupun yang berskala besar. Hal ini memiliki pengaruh yang sangat penting pada penggunaan waktu yang efektif dan tingkat angka penjualan. Maka dari itu e-commerce atau toko online harus mempunyai kemampuan menilai sarana yang digunakan untuk mengetahui dan mengklasifikasikan niat pembelanjaan online sehingga menghasilkan keuntungan bagi toko tersebut. Niat pembelanja online dapat dilakukan pengklasifikasian menggunakan beberapa algoritma, seperti Naive Bayes, Random Forest dan Support Vector Machine. Dalam penelitian ini perbandingan algoritma dilakukan menggunakan aplikasi WEKA dengan mengetahui nilai F1-Score, Akurasi, Kappa Statistic dan Mean 
Absolute Error. Terdapat perbedaan antara hasil pengujian, untuk nilai F1-Score, Akurasi, Kappa Statistic menghasilkan pengujian algoritma Random Forest-lah yang paling baik dibandingkan Naive Bayes dan Support Vector Machine. Sedangkan pada nilai Mean Absolute Error hasil pengujian algoritma Support Vector Machine merupakan nilai terbaik dari pada Naive Bayes dan Random Forest. Sehingga berdasarkan penelitian ini Algoritma Random Forest merupakan algoritma yang paling baik dan tepat untuk diterapkan sebagai pengklasifikasian niat pembelanja online, karena algoritma Random Forest yang paling mendominasi dalam mengetahui nilai kriteria seperti F1-Score, Akurasi, Kappa Statistic dan Mean Absolute Error.

Kata Kunci-Algoritma, E-Commerce, Machine Learning, Niat Belanja, Weka.

\section{PENDAHULUAN}

Beberapa tahun terakhir ini, penggunaan e-commerce atau toko online sangat meningkat. Bermacam-macam toko online yang bermunculan di internet, baik berskala kecil maupun yang berskala besar. Bahkan toko offline pun yang dulu hanya membuka di toko/ruko sekarang beralih ke toko online dan menutup toko/ruko nya. Sehingga konsumen dapat mencari barang selama 24 jam, bahkan dari luar kota maupun luar negeri, begitu juga hal nya penjual mendapatkan konsumen di seluruh dunia.

Pengalaman ini memiliki pengaruh yang sangat penting pada penggunaan waktu yang efektif dan tingkat angka penjualan. Banyak perusahaan $e$ commerce berinventasi dalam deteksi dini (Sakar, S. Olcay Polat, Katircioglu, \& Kastro, 2018). Walaupun e-commerce ini banyak bermunculan dan sedang tenar, akan tetapi banyak juga masyarakat tidak semuanya tertarik. Banyak toko online yang gagal dan tidak berhasil untuk memperoleh keuntungan, karena konsumen merasa toko online tersebut menjadi sarana jual/beli yang kurang menarik (Christian, 2019).

$$
\text { Dapat disimpulkan bahwa }
$$

kenyamanan layanan toko online menjadi penentu perilaku konsumen (Khan \& Khan, 2018). Dan juga rekomendasi verbal dari keluarga dekat, kerabat, teman atau bahkan penilaian pada bintang di toko tersebut (Liao, Lin, Luo, \& Chea, 2016).

Toko online harus mempunyai kemampuan untuk menilai sarana yang digunakan, sehingga dapat mengetahui dan mengklasifikasikan niat pembelanja online, maka diperoleh keuntungan dari hasil penjualan. Kemampuan ini dapat di aplikasikan pada toko online dengan cara menggunakan algoritma machine learning.

Dengan menggunakan dua modul jenis algoritma machine learning dan prediksi yang paling baik, dalam hal ini algoritma yang digunakan yaitu algoritma multilayer perceptron (Sakar et al., 2018). 
Pada penelitian kali ini fokus dalam perbandingan algoritma machine learning manakah yang palik baik, untuk menilai niat dan potensi belanja konsumen dengan menggunakan tools WEKA, sehingga perbandingan algoritma mendapatkan hasil akurat dan yang paling baik, dan toko tersebut memperoleh pendapatan yang sesuai.

\section{Data Mining}

Data mining merupakan salah satu cabang ilmu komputer yang populer. Menurut David Hand, Heikki Mannila dan Padharic Smyth dari MIT dalam jurnal (Nurachim, 2019) Data Mining merupakan analisa terhadap data (biasanya data yang berukuran besar) untuk menemukan hubungan yang jelas serta menyimpulkan yang belum diketahui sebelumnya dengan cara dipahami dan berguna bagi pemilik data tersebut.

\section{Machine Learning}

Istilah Machine Learning mengacu pada deteksi otomatis dari pola yang bermakna dalam data. Machine learning adalah salah satu cara manusia untuk mengajarkan sesuatu kepada computer. Tanpa melakukan pemrograman tertentu secara eksplisit komputer dapat belajar untuk mengolah data-data yang diberikan kepadanya. Algoritma machine learninglah yang berperan untuk mengajarkan pengolahan data kepada computer
(Christian, 2019).

\section{Algoritma Klasifikasi}

Naive Bayes adalah Algoritma sederhana dan lugas yang didasarkan pada teorema Bayes untuk probabilitas bersyarat. Hal ini untuk mengklasifikasi data tergantungpada frekuensi terjadinya deskriptor data dari set pelatihan. Asumsi algoritma Naive Bayes adalah semua data sama-sama independen. Dengan asumsi ini, algoritma menemukan ketergantungan antara fitur dari pelatihan (Kabir, Ashraf, \& Ajwad, 2019).

Support Vektor Machine (SVM) merupakan metode klasifikasi jenis terpadu (supervised) karena ketika proses pelatihan perlu target pembelajaran tertentu (Nurachim, 2019).

Random Forest yaitu konsep untuk membuat sejumlah besar pohon keputusan berkolerasi dimana semua pohon keputusan bertindak sebagai model ansambel. Setiap pohon keputusan meletakkan prediksi kelas dan keputusan akhir didasarkan pada hasil maksimum (Kabir et al., 2019).

Beberapa penelitian terkait yang dilakukan dalam penerapan data mining menggunakan multilayer perceptron yang pernah dilakukan menggunakan dua modul (Sakar et al., 2018). Ada juga Perbandingan Model Algoritma Machine Learning dengan Menggunakan WEKA 
dan Sci-Kit Learn Dalam

Mengklasifikasikan Niat Pembelanja

Online (Christian, 2019). Service

Convenience and Post-Purchase

Behaviour of Online Buyers : An

Empirical Study(Khan \& Khan, 2018).

Factors Influencing Online Shoppers'

Repurchase Intentions: The Roles of

Satisfaction and Regret (Liao et al., 2016).

Analysis of Different Predicting Model for

Online Shoppers' Purchase Intention from

Empirical Data (Kabir et al., 2019). The

Effect of Product Review Balance and

Volume on Online Shoppers' Risk

Perception and Purchase Intention (Yang,

Sarathy, \& Lee, 2016). Real-Time

Prediction of Online Shoppers' Purchasing Intention Using Random Forest (Baati \& Mohsil, 2020).

\section{METODE PENELITIAN}

\subsection{Tahap Penelitian.}

Pada penelitian ini diawali dengan pengambilan data dari website $U C I$ Machine Learning Repository. Selanjutnya data diolah menjadi data awal yang akan di proses menggunakan tools WEKA 3.8.2. Lalu diuji dengan algoritma dengan nilai objek yang sama.

Terdapat tiga buah algoritma yang akan dibandingkan menggunakan tools tersebut yakni algoritma Naive Bayes,
Support Vector Machine dan Random Forest. Setelah data diproses dan diuji, selanjutnya yaitu menganalisa data yang dihasilkan dari tools WEKA dengan tiga buah algoritma machine learning. Sehingga mengahasilkan algoritma yang paling baik untuk diterapkan pada data tersebut.

Tahapan Penelitian yang dilakukan dijelaskan pada Gambar 1 berikut dibawah ini (Christian, 2019) :

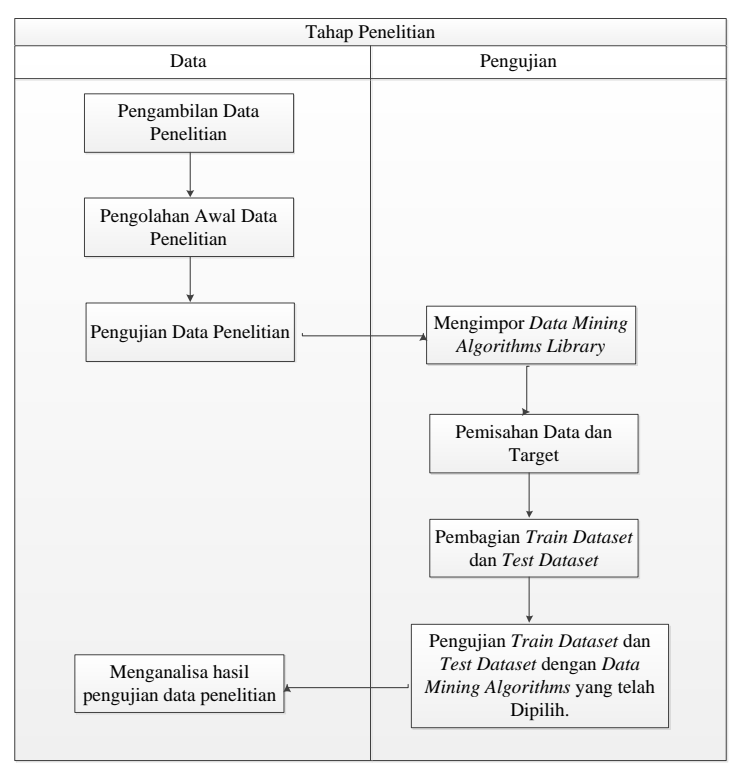

Gambar 1. Tahapan Penelitian

\subsection{Data Yang Digunakan}

Data yang dipakai dalam penelitian ini yaitu dataset "Online Shoppers Purchasing Intention Dataset" yang diambil dari halaman website $U C I$ Machine Learning Repository. C. Okan Sakar, Mete Alpaslan Katircioglu, S. Olcay Polat dan Yomi Kastro pada tahun 2018 menggunakan penelitian dataset ini. 
Dengan judul penelitian "Real time prediction of online shoppers' purchasing intention using multilayer perceptron and LSTM recurrent neural networks". Jumlah contoh datanya ada 12.330 yang diambil oleh penyedia dari berbagai macam website jual beli. Berikut ini contoh data tersebut sebagian.

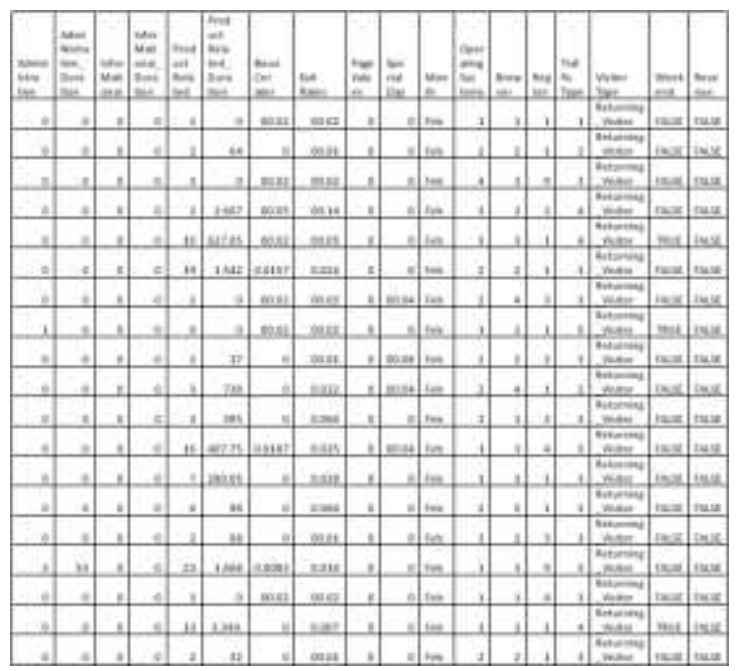

Gambar 2. Data Yang Digunakan

Sumber:

https://archive.ics.uci.edu/ml/datasets/Onli $n e+$ Shoppers+Purchasing+Intention+Data set.

\section{HASIL DAN PEMBAHASAN}

\section{1. Pengujian Pada Aplikasi WEKA}

Pengujian menggunakan aplikasi WEKA dilakukan dengan melihat dan memperhatikan nilai-nilai objek pada masing-masing algoritma yang digunakan, dalam penelitian ini terdapat tiga algoritma yang digunakan yaitu Naive Bayes, Random Forest dan Support Vector Machine (SVM). Gambar 3 merupakan nilai objek menggunakan algoritma Naive Bayes.

Sesuai dengan algoritma yang akan digunakan. Melalui aplikasi WEKA dapat dihasilkan data pengujian pada Gambar 4.

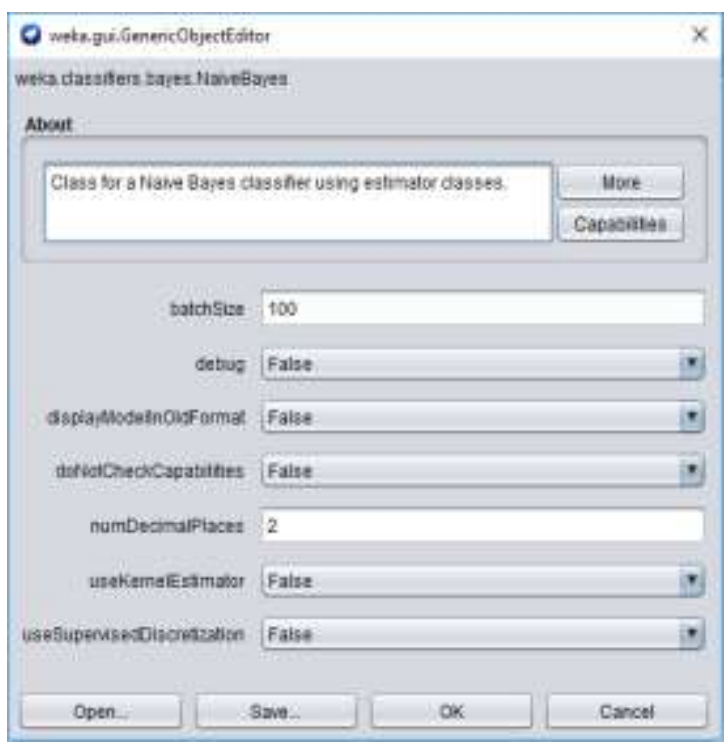

Gambar 3. Penentuan Nilai Objek algoritma Naive Bayes pada WEKA

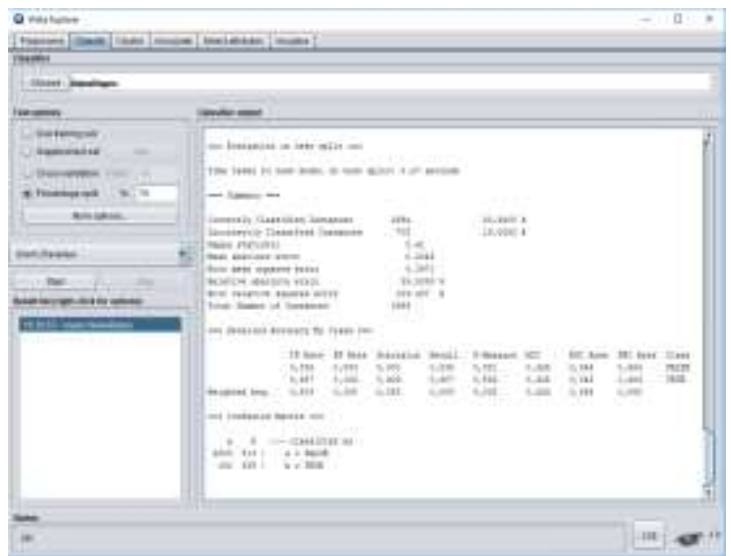

Gambar 4. Hasil Data Menggunakan

Algoritma Naive Bayes pada WEKA

Pada pengujian data set online shoppers purchasing intention yang diatas dengan menggunakan metode Naive Bayes menghasilkan tingkat keberhasilan $80,9 \%$ dan error $19,1 \%$. 
Pengujian berikutnya yaitu menggunakan metode Random Forest yang dilakukan dengan melihat dan memperhatikan nilai-nilai objek pada Gambar 5.

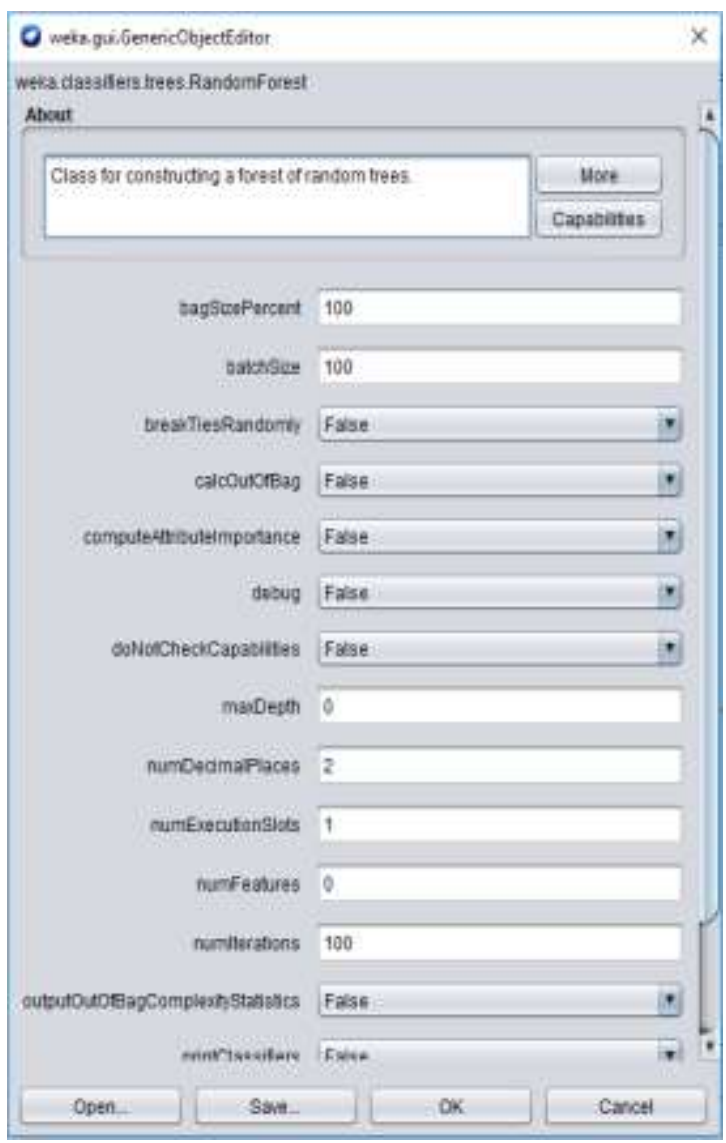

\section{Gambar 5. Penentuan Nilai Objek} algoritma Random Forest pada WEKA

Dengan algoritma yang digunakan yaitu Randon Forest melalui pengujian di aplikasi WEKA, maka dapat dihasilkan pada Gambar 6.

Sehingga dari pengujian tersebut dengan menggunakan metode Random Forest menghasilkan tingkat keberhasilan $89,9 \%$ dan error $10,1 \%$ dapat dilihat pada Gambar 7.

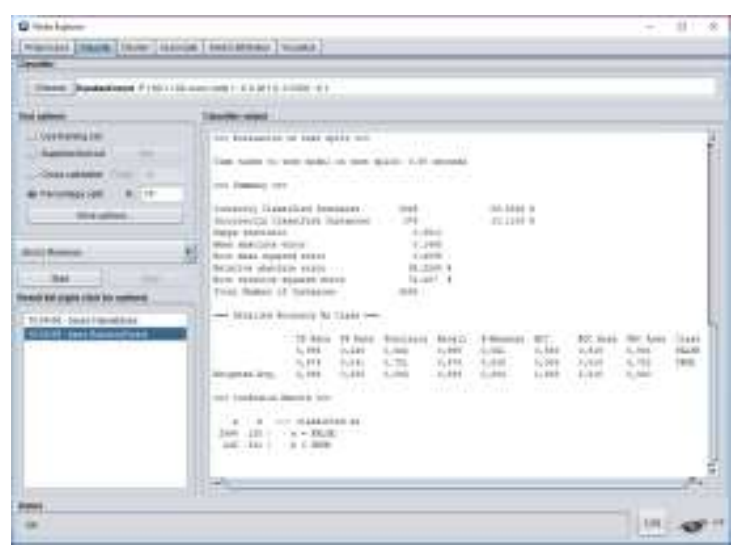

Gambar 6. Hasil Data Menggunakan

Algoritma Random Forest pada WEKA

Selanjutnya

pengujian

menggunakan algoritma Support Vector Machine (SVM), nilai-nilai objek dapat dilihat Gambar 7.

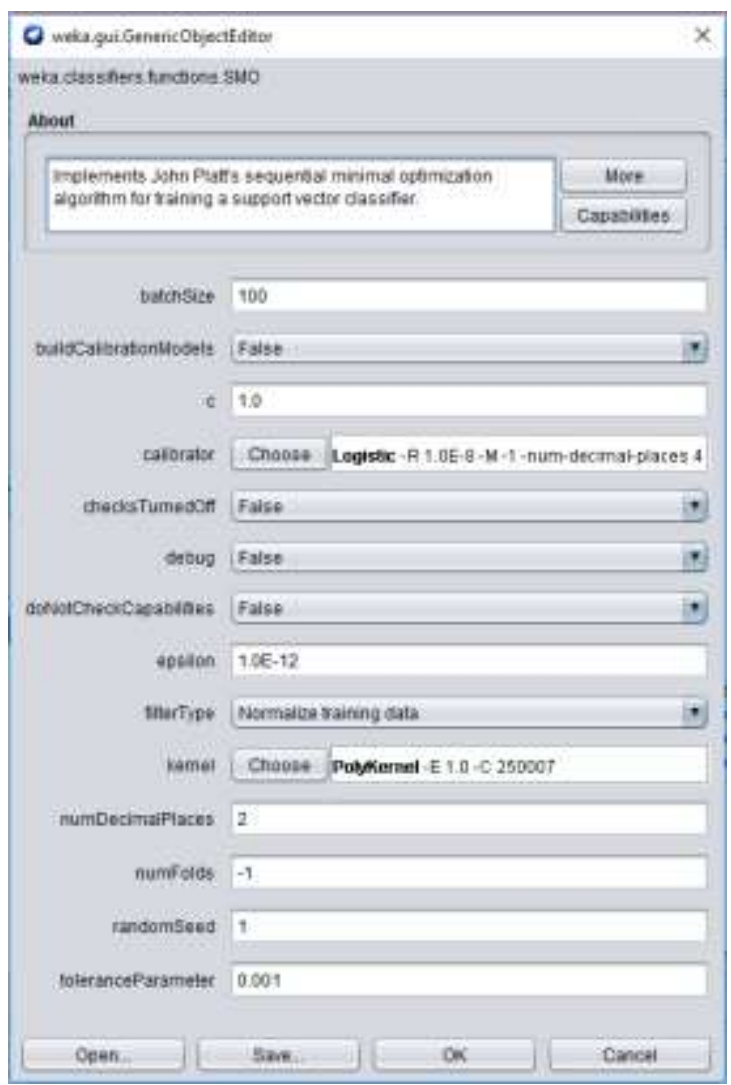

Gambar 7. Penentuan Nilai Objek algoritma SVM pada WEKA

Algoritma SVM dapat mengasilkan nilai pengujian tingkat keberhasilan 
$88,02 \%$ dan errornya yaitu $11,97 \%$ dapat dilihat pada Gambar 8.

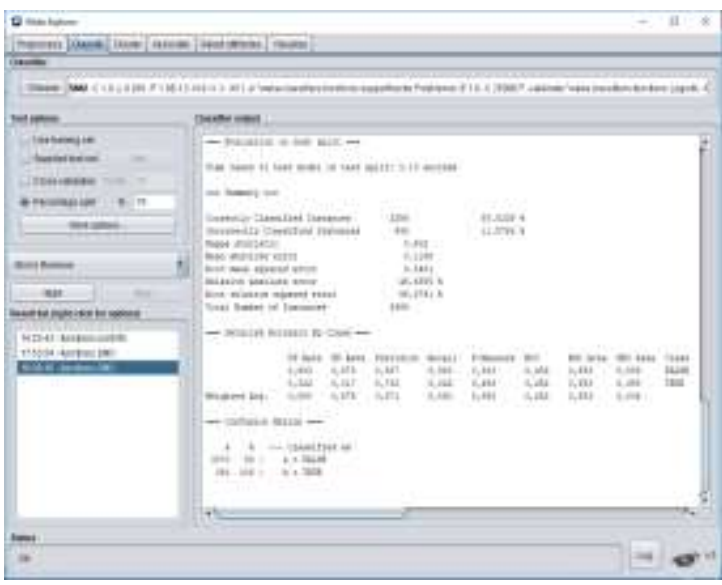

\section{Gambar 6. Hasil Data Menggunakan}

\section{Algoritma $S V M$ pada WEKA}

Dari data hasil yang diperoleh pengujian menggunakan aplikasi WEKA berisi nilai-nilai tertentu dan untuk membandingkan algoritma klasifikasi sebaik apa data yang akan dipilih dari hasil nilai f1-score, akurasi, Kappa Statistic, mean absolute error dari setiap algoritma yang diterapkan. Hasil ringkasan pengujian data tercandum dalam tabel 1 dibawah ini.

Tabel 1. Hasil Pengujian Data pada Aplikasi WEKA

\begin{tabular}{|c|c|c|c|c|}
\hline Classifier & $\begin{array}{c}\text { F1- } \\
\text { Score }\end{array}$ & Akurasi & $\begin{array}{c}\text { Kappa } \\
\text { Statistic }\end{array}$ & MAE \\
\hline $\begin{array}{c}\text { Naive } \\
\text { Bayes }\end{array}$ & 0,825 & $80,9 \%$ & 0,41 & 0,234 \\
\hline $\begin{array}{c}\text { Random } \\
\text { Forest }\end{array}$ & 0,894 & $89,9 \%$ & 0,581 & 0,144 \\
\hline SVM & 0,858 & $88,02 \%$ & 0,119 & 0,119 \\
\hline
\end{tabular}

\section{2. Hasil F1-Score}

F1- skor adalah ukuran yang paling banyak digunakan dalam evaluasi berbasis batas, memperkenalkan kerangka presisi-recall (Avola et al., 2019).

Dari hasil data yang diuji menggunakan aplikasi WEKA, algoritma Random Forest menghasilkan nilai 0,894. Untuk nilai F1-Score itu sendiri, nilai yang paling baik yaitu 1 . Sehingga nilai 0,894 merupakan nilai yang paling mendekati 1 dari ke tiga algoritma yang lain. Jadi algoritma Random Forest merupakan algoritma yang paling baik pada nilai F1-Score. Sedangkan algoritma Naive Bayes merupakan nilai F1-Score yang terburuk karena mendekati nilai 0 dengan hasil 0,825 .

\section{3. Hasil Akurasi}

(Baati \& Mohsil, 2020) menyimpulkan nilai yang menyajikan akurasi rata-rata yang tertinggi semakin baik algoritmanya.

Hasil dari data yang diuji menggunakan aplikasi WEKA, maka pengklasifikasian data menggunakan algoritma Random Forest menghasilkan nilai akurasi tertinggi yaitu dengan nilai $89,9 \%$, dibandingkan nilai akurasi yang lain yang paling rendah adalah Naive Bayes dengan nilai 80,9\%. 


\section{4. Hasil Kappa Statistic}

(Kavitha \& Manikandan, 2019) menyimpulkan untuk menemukan derajat kesesuaian yaitu menggunakan Kappa Statistic, yang menghasilkan interval 0 dan 1. Maka semakin tinggi nilai Kappa Statistic semakin baik pula algoritma yang dipakai.

Dari pengujian data menggunakan aplikasi WEKA, hasil yang digunakan dalam pengklasifikasian data yang paling tinggi menggunakan algoritma Random Forest, dengan nilai Kappa Statistic 0,581. Sedangkan untuk nilai Kappa Statistic yang terendah dihasilkan dari algoritma Naive Bayes yakni 0,41.

\section{5. Hasil Mean Absolute Error}

Mean Absolute Error adalah salah satu metode yang digunakan untuk mengukur tingkat keakuratan model peramalan. Nilai MAE menunjukan ratarata kesalahan (error) absolut antara hasil peramalan/prediksi dengan nilai riil (Suryanto \& Muqtadir, 2019).

Dari data yang diuji menggunakan aplikasi WEKA, maka hasil mengklasifikasian data menggunakan algoritma SVM-lah yang merupakan nilai mean absolut error nya paling rendah dengan nilai 0,11 dan untuk nilai mean absolut error tertinggi algoritma Naive Bayes 0,234.

\section{SimPULAN}

Dari hasil pengujian pada penjelasan sebelumnya terdapat hasil yang berbeda pada mean absolut error.

Untuk nilai F1-Score, Akurasi dan Kappa Statistic, menghasilkan posisi kedudukan nilai yang sama, dan sesuai dengan kriteria dari masing-masing algoritma. Pada ketiga penilaian tersebut, algoritma Random Forest-lah yang merupakan algoritma paling baik dibandingkan algoritma SVM dan Naive Bayes.

Maka dari itu dapat diambil kesimpulan bahwa algoritma Naive Bayes dan Support Vector Machine merupakan algoritma yang tidak direkomendasikan untul penilaian data Online Shoppers Purchasing Intention Dataset.

Sehingga dalam penelitian kali ini, algoritma Random Forest yang paling baik untuk digunakan dalam pengklasifikasian data Online Shoppers Purchasing Intention Dataset. Karena algoritma Random Forest yang paling mendominasi dalam mengetahui nilai kriteria seperti F1Score, Akurasi, Kappa Statistic dan Mean Absolute Error.

\section{DAFTAR PUSTAKA}

[1] Avola, D., Cinque, L., Foresti, G. L., Lamacchia, F., Marini, M. R., Perini, 
L., ... Telesca, G. (2019). A Shape Comparison Reinforcement Method Based on Feature Extractors and F1Score, 2155-2159.

[2] Baati, K., \& Mohsil, M. (2020). RealTime Prediction of Online Shoppers ' (Vol. 1). Springer International Publishing.

https://doi.org/10.1007/978-3-03049161-1

[3] Christian, Y. (2019). JITE (Journal of Informatics and Telecommunication Engineering), 3(1), 58-66.

[4] Kabir, R., Ashraf, F. Bin, \& Ajwad, R. (2019). Analysis of Different Predicting Model for Online Shoppers ' Purchase Intention from Empirical Data, (March 2020). https://doi.org/10.1109/ICCIT48885. 2019.9038521

[5] Kavitha, S., \& Manikandan, S. (2019). Improving the Automobile Purchasing Behavior of Customer: Classification Techniques, (2), 22192223.

https://doi.org/10.35940/ijeat.B2924. 129219

[6] Khan, M. A., \& Khan, S. (2018). Service Convenience and PostPurchase Behaviour of Online Buyers: An Empirical Study, 167188. https://doi.org/10.1007/s12927018-0006-X
[7] Liao, C., Lin, H., Luo, M. M., \& Chea, S. (2016). Factors influencing Online Shoppers' Repurchase Intentions: The Roles of Satisfaction and Regret. Information \& Management. https://doi.org/10.1016/j.im.2016.12. 005

[8] Nurachim, R. I. (2019). Pemilihan Model Prediksi Indeks Harga Saham Yang Dikembangkan Berdasarkan Algoritma Support Vector Machine ( Svm ) Atau Multilayer Perceptron ( Mlp ) Studi Kasus : Saham Pt Telekomunikasi Indonesia Tbk Jurnal Teknologi Informatika \& Komputer | Vol . 5 , No . 1, Maret 2019, 5(1), 29-35.

[9] Sakar, C. O., S. Olcay Polat, Katircioglu, M., \& Kastro, Y. (2018). Real-time prediction of online shoppers ' purchasing intention using multilayer perceptron and LSTM recurrent neural networks. Neural Computing and Applications, 0. https://doi.org/10.1007/s00521-0183523-0

[10] Suryanto, A. A., \& Muqtadir, A. (2019). Penerapan Metode Mean Absolute Error ( Mea ) Dalam Algoritma Regresi Linear Untuk Prediksi Produksi Padi, (1), 78-83.

[11] Yang, J., Sarathy, R., \& Lee, J. (2016). AC Management Science and 
Information Systems. Decision

Support

Systems.

https://doi.org/10.1016/j.dss.2016.06.

009

[12] Fitria, Y. A. (2019). Visualization of data on earthquake prone areas from the analysis of earthquake data vibrations. Test Engineering and Management, 81(11-12).

[13] Yulmaini, Y., Sanusi, A., \& Yusendra, M. A. E. (2018). The Implementation of AHP for Determining Dominant Criteria in Higher Education Competitiveness Development Strategy Based on Information

Technology. International Journal of Artificial Intelligence Research, 3(1).

[14] Yuliawati, D., Saleh, S., \& Indera, I. (2018). Prototype Pengadaan Dan Distribusi Barang Pada Waralaba Fried Chicken dan Burger lampung. SIMADA (Jurnal Sistem Informasi dan Manajemen Basis Data), 1(1), 61-70.

[15] Azhari, A., \& Lestari, S. (2019, December). Forecasting The Number Of Customers Using The BoxJenkins (Arima) And Linear Regressionmethod (Case Study: PT. AIA Financial LPG Sunrise Agency). In Prosiding International conference on Information Technology and Business (ICITB) (pp. 206-217).

[16] Purbo, O. W., Sriyanto, S., Irianto, S. Y., Aziz, R. Z., \& Herwanto, R. (2020). Benchmark and comparison between hyperledger and MySQL. TELKOMNIKA

Telecommunication, Computing, Electronics and Control, 18(2), 705715.

[17] Jeprianto, J., \& Aziz, R. A. (2020). Implementasi Algoritma Rough Set Dan Naive Bayes Untuk Mendapatkan Rule Dalam Menyeleksi Pemohon Bantuan Fasilitas Rumah Ibadah (Studi Kasus: Pemerintah Kabupaten Pringsewu). JTKSI (Jurnal Teknologi Komputer dan Sistem Informasi), 3(2), 74-83.

[18] Fitria, S. Y., \& SeptiliaArfida, H. Green Cloud Computing Ideas with Security Issues in Setting of Distributed Computing and Cloud Framework. 